\title{
Development of Internet of Things Systems for Monitoring Agricultural Silos
}

\author{
O. I. Ekuewa, E.O. Ogunti, and J. B. Ekuewa
}

\begin{abstract}
Internet of things is a recent advancement in the technological world. Agriculture being the art and science of cultivating the soil, growing crops, and raising livestock for human consumption requires a day-to-day monitoring and observation of the farm produce. Internet of things enables farmers to obtain data surveys and monitor their farm and storage facilities in real-time. This research is addressing a logical study of the current and potential application of internet of things IoT in agricultural silos, where spatial data, highly varying physical environmental factors, task diversity and mobile devices pose a sole challenge to be overcome compared to other agricultural systems. In this research, a smart security and monitoring device is developed for Agricultural products (Maize) using the Internet of things to observe and preserve storage environment both physically and autonomously. Data is deposited in MySQL database and the communication with the sensed data and webserver is recognized with the help of Arduino. The research is supported by smart phone via android app which increases its flexibility. Monitoring and documenting of data can be achieved on the android app. The system is tested on standardized silo and the result was as expected. The result of the study established that there is a slight difference between the Temperature $\left(17-31{ }^{\circ} \mathrm{C}\right)$ and Humidity $(52-78 \%)$ obtained from the device and optimum Temperature $\left(18-27{ }^{\circ} \mathrm{C}\right)$ and Humidity $(62-70 \%)$ required for maize storage which makes it a better method when compared with the conventional method of storing maize. The result obtained further shows that temperature, humidity, and moisture content contributed to losses in weight of the maize stored if not monitored and maintained during the research period.
\end{abstract}

Keywords - Arduino, IoT, Mobile App, Monitoring.

\section{INTRODUCTION}

Monitoring of stored grain conditions and the capability of transmitting the information(data) has become a vital challenge to guarantee its security. It is imperative to have adequate, secure and stocks of grain. However, post-harvest stored grain is lost by around $7 \%$ to $15 \%$ due to inappropriate storage [1]. Since it is the most consumed food over the decades, instead of chemical means of preserving it for a longer period which may result in some deficiency while consuming, it is paramount to implement a measure to ensure a proper and adequate storage system. Full grains must be kept a bit more cautiously than their refined counterparts

Submitted on December 17, 2021.

Published on January 14, 2022.

O. I. Ekuewa, Department of Electrical and Electronics Engineering, Federal University of Technology Akure, Nigeria.

(e-mail: ekuewao@gmail.com)

E. O. Ogunti, Department of Computer Engineering, Federal University

of Technology Akure, Nigeria.

(e-mail: oguntig@gmail.com) meanwhile the healthy oils of whole grains can be negatively affected by heat, light and moisture which causes germ in the grain mass. The inability to consider environmental conditions of storage facility such as grain's temperature, humidity, moisture content, level of gases like $\mathrm{CO}_{2}$ leads to the presence of pests, microorganisms, and fungi in grain. Humidity, temperature, and grain moisture content are the key features responsible for the decomposition of grain due to the increase in metabolic action and growth of pests inside the grain mass [9]. Pest damages the seed, externally as well as internally. Gathering environmental data using conventional and present methods such as visual inspection, grain probes and insect traps, uric acid measurement technique, radiographic technique, NIR spectroscopy, X-ray imaging is labour-intensive, expensive, imprecise, and inconvenient [2]. Hence, there is a necessity for a real-time electronic monitoring sensing system that is not labourintensive, accurate, quick, and cost-effective. The collected data so obtained can be used for analysis for forecasting the condition of grain and to make decisions for the end-users to take precautionary measures, which can monitor the environment in which grain is stored, such as silos, bags and metallic bins. To provide good quality agricultural products, it is imperative to sustain an adequate and optimum temperature and humidity in either a storehouse, warehouse or silo when storing the agricultural produce. Environmental temperature and relative humidity are the two most important factors influencing grains viability and longevity during storage. Interdependence of these two factors during storage and their subsequent effects on grain moisture cannot be overemphasized. Biological processes during the storage of grain arouse instinctively rising temperature which is unbidden for. While the major food crops such as cereal, grains, tubers, and potatoes, are normally seasonal crops, grains which are the world's most important staple food face difficulties in storage. Unfortunately, most of the farmers in our country use traditional ways of storage which are hectic processes for analyzing data manually relating to crops. An autonomous control system will help to maintain the desired temperature valued for proper storing. Temperature variation, which is the key aspects of storage, together with monitoring the humidity attest that the products had been stored in a properly [3]. Lately used wire-based measuring systems of the temperature

J. B. Ekuewa, Department of Computer Science, Federal Polytechnic Ede, Nigeria.

(e-mail: ekuewa2013@yahoo.com) 
and humidity have appropriate measurements precision and reliable data storage. Their shortcomings though are the wired connection laid in the potato stack often interrupt when work is done in the storage facility (e.g., emptying the store), wires in the store frequently break resulting in loss of signals.

Consequently, the primary goal of any storage system must be to maintain the crops in its prime conditions for as long as possible. The storing, supervision and management approaches should minimize losses, also it must be suitable in relation to other factors, such as economies of scale, labour cost and accessibility, structure costs and equipment cost. Conventional knowledges for food processing and preservation date back thousands of years have their consequences, unlike now that electronic knowledge and other modern high technology advancements, which have long preceded any expert understanding. Traditional foods and traditional food processing and preservation methods form part of the culture of the people. Traditional food processing and safeguarding measures create a vital body of native knowledge handed down from parent to child over several generations. Regrettably, this vital body of native knowledge is often underrated. Also, some of the traditional food products and food processing practices of people have certainly been lost over the years [4].

Internet of things (IoT) technology has become pervasive, which has affected almost every crook of the globe and is affecting human life in unbelievable ways. However, the expedition is far from over. We are now entering a period of even more pervasive connectivity where a very wide variability of appliances will be connected to the web. We are entering an era of the "Internet of things". Internet of things (IoT) can be defined as simply an interaction between the physical and digital worlds [5]. The digital world relates with the physical world using a plethora of sensors and actuators. [6] define the Internet of Things as an example in which computing and interacting abilities are embedded in any kind of conceivable object. These abilities are used to question the state of the object and to change its state if possible. Likewise, the internet of things refers to a new kind of world where almost all the devices and appliances that we use are linked to a network. It can be used collaboratively to attain complex tasks that need a high degree of intellect. For this intellect and interdependence, IoT systems are armed with embedded sensors, actuators, processors and transceivers. Sensors and actuators are made used of for interaction with the physical world. The data collected by the sensors have to be stored and processed logically in order to derive valuable interpretations from it. An actuator is a device that is used to alter a variation in the environment such as the temperature controller of an air conditioner. Storing and processing of data can be done on the authority of the system itself or on a remote server. The storage and processing abilities of an IoT object are also constrained by the resources available, which are often very restricted due to limits of size, power, computational capability, and energy. Interaction between IoT systems is mostly wireless because they are usually installed at geographically dispersed locations. The wireless channels frequently have high rates of distortion and are defective [7]. The mechanical devices owning the ability of transmission of data over the distinct network internet of things (IoT) is a well-defined arrangement of digital, interrelated computing strategies, and without having human involvement at any level. All these systems are related with their precise unique documentation with their codes. IoT is now well recognized and proven technology that acts as a junction to the countless tactics, instantaneous analytics, philosophy of machine learning, sensory products. Internet of Things (IoT) can be applied in various areas such as Home automation, smart cities, social life and environment, health fitness, smart environment and agriculture, supply chain and logistics, energy conservation and so on.

\section{METHODS}

The recent technological advancement has created efficiency and adequate monitoring and security system for our day-to-day activities. Considering the monitoring and security challenges encountered in storage facilities, there is a need to analyze data and transmit information over the network to remote locations. In design, grain monitoring is done where sensors are used to collect information in the storage aspect of the agricultural field. This system makes use of the Internet of Things (IoT) that have the ability to transmit data in real-time to facilitate grain monitoring for the protection of the grain so that it would not get contaminated due to the surrounding conditions during storage. Efficient monitoring of temperature, humidity, moisture content and other conditions are required for maize storage. Here, the main purpose is to observe, secure and monitor the storage environment thus making the admin manage the data in realtime. Figure 1 shows the block diagram of the system. Under this section, the technical procedures, flowchart, sensors to be employed, system integration, fabrication and the experimental procedure are discussed.

\section{A. System Design}

The sensors and components used in the design and implementation of the system were well selected to perform the required operations. The software controlling device is programmed in the Arduino microcontroller. The design is further broken down into two essential parts: Hardware subsystem and software sub-system.

\section{B. Hardware Sub-system}

Fig. 1 shows the schematic diagram of the different functional interfaces that make up the hardware subsystem comprising of the sensor units, the microcontroller units and

power supply units. Hardware design focused on processing the signal coming from the sensors using microcontroller technology. The system block diagram describes the

relationship between the sensors and the processor and is divided into six units:

i. Power Supply Unit: This is the unit converts that alternating-current $\mathrm{AC}$ from a wall socket to a low-voltage direct-current DC also known as rectification to operate the processor and peripheral devices and also charges the battery. Here, both the A.C supply and the D. C supply are put into consideration for the efficiency of the device.

ii. Processing Unit: This unit is made up of a microcontroller and it is the major brain of the system where instructions are passed to control both the input and output 
activities in the system. Here Arduino ATMEGA328 was chosen for this purpose.

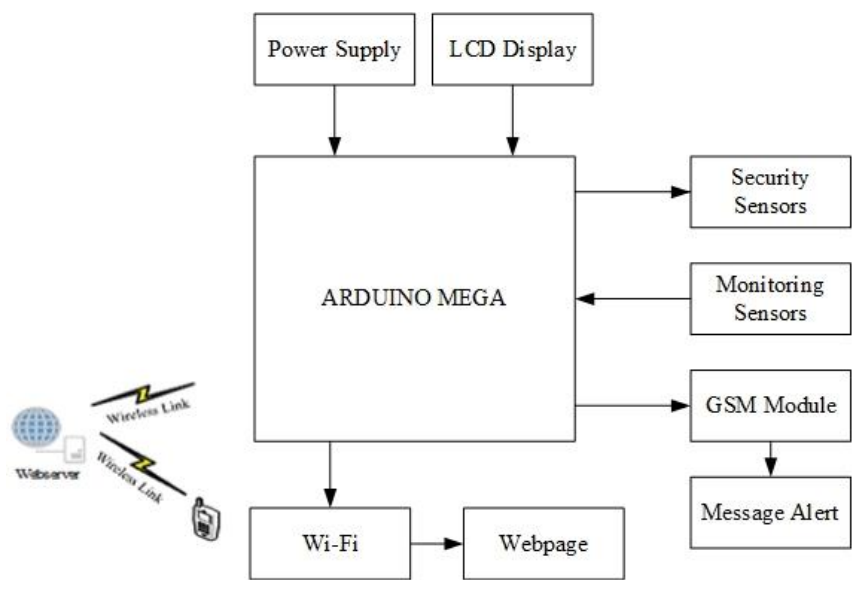

Fig. 1. System Block Diagram.

iii. Sensing Unit: This is the unit that is responsible for the detection of environmental changes and sends the information to the microcontroller. This comprises the Temperature sensor, Humidity sensor, Moisture content sensor, Passive infrared sensor (PIR) and a Flame sensor for the purpose of monitoring and security.

iv. Transmitting Unit: The information sensed by the sensors are transmitted in this unit to the receiving end, this unit is made of the GSM/GPRS module.

v. Data-Collection Unit: This is also known as the reception unit, where the information transmitted is received, here a user-friendly Mobile app is developed, and the information can also be saved in the system SDcard.

vi. Switching Unit: This is majorly where the controlling operation is done to maintain the optimum parameter values of the physical environmental factors in the storage facility. This comprises of Electro-magnetic relay, normally open push-button and Reset button.

As shown in Fig 1, the sensors are categorized under monitoring sensors and security sensors, under which the system is compose of five different electronic sensors which are designed to perform the function of updating the conditions of the grain storage facility. The moisture sensor, humidity and temperature sensor are the monitoring sensor while the smoke sensor and the passive infrared sensor are the security sensors. The information collected by the sensors is sent to the Arduino microcontroller ATmega. The time and date are displayed on a Liquid crystal display (LCD) since it is a real-time sensing device. A webpage is created, and the information collected by the sensors are updated periodically through Wi-Fi. The GSM module allowed the microcontroller to communicate the data from the sensors and devices to the webserver and the microcontroller that processes the signals from each component of the system.

Lastly, a Mobile app was developed that serves as the platform for saving the data from the webserver and displaying it in a format that the user will understand. Data from the Mobile app can be in an excel file for further analysis. The microcontroller uses a periodic time-triggered method to read the sensor values and send the data to the webserver.

\section{MAIN HARDWARE COMPONENTS}

Hardware design focused on processing the signal coming from the sensors using microcontroller technology. The system block diagram describes the relationship between the sensors. The sensors and the hardware component were selected based on the identified physical parameters responsible for good storage.

\section{A. Arduino MEGA}

The Arduino Mega is a microcontroller board created on the ATmega328. It has 54 digital input/output pins (of which 14 can be used as Pulse Width Modulation outputs), 16 analogue inputs, 4 UARTs (hardware serial ports), the USB connection, a power jack, an ICSP header, and a reset button. It contains every provision microcontroller will be needing; simply connect it to a computer with a USB cable or power it with an AC-to-DC adapter or battery to get started. The monitoring system required a total of 10 digital pins and 5 analogue pins making the Arduino MEGA a perfect candidate. The MEGA has a clock speed of $16 \mathrm{MHz}$ and a flash memory of $32 \mathrm{~KB}$ which was more than enough to run and process the monitoring system code. ATmega-328, developed by Arduino. cc was the micro-controller selected serving as the sensor node processing unit. It is an Advanced Virtual RISC (AVR) micro-controller. All the data obtained through respective sensors are processed by the Arduino micro-controller through the digital pins. An Analogue-todigital converter (ADC) at 10-bit resolution does the work of converting the analogue value from the sensor to digital value for smooth operation by the microcontroller. It converts the voltage measurements in the range $0-1023$, when a voltage of $5 \mathrm{~V}$ is provided to the probes, a resolution of about $0.005 \mathrm{~V}$ $(5 / 1023)$ is obtained.

Output data from the Arduino microcontroller is transmitted to the base station via GSM/GPRS module. Specifications of the Arduino MEGA are given in Table I.

TABLE I: ARDUINO MEGA SPECIFICATION

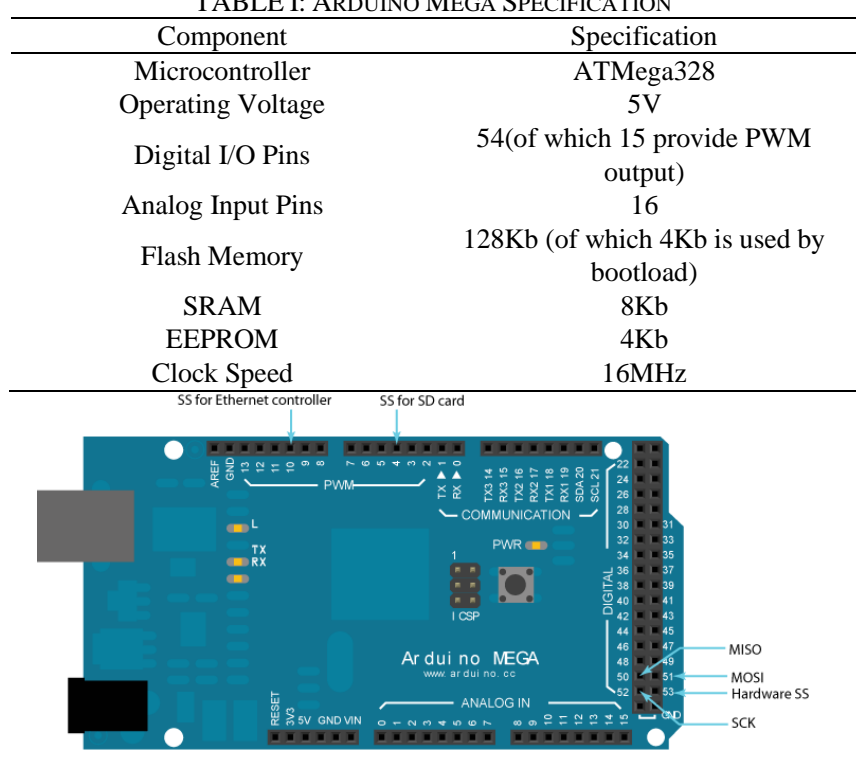

Fig. 2. Arduino Mega.

\section{B. DHT11 Temperature and Humidity Sensor}

The DHT11 is a dual temperature and humidity sensor, meaning that it can sensed both Humidity and temperature. A 
higher accuracy temperature sensor is implemented instead. This sensor uses serial communication that is reliable and has long-term stability. In this research, I use this sensor for taking the storage internal temperature and humidity as well as then sending it to the webserver for real-time monitoring purposes. The technical requirement is shown in Table II.

TABLE II: TECHNICAL REQUIREMENT: DHT11 MODULE

\begin{tabular}{ccc}
\hline Requirement & Humidity sensor & Temperature sensor \\
\hline Power supply & $3.3-6 \mathrm{~V} \mathrm{DC}$ & $3.3-6 \mathrm{~V}$ DC \\
Output signal & digital signal & Digital signal \\
Sensing element & Polymercapacitor & Polymercapacitor \\
Operating range & $0-100 \% \mathrm{RH}+-2 \% \mathrm{RH}$ & $-40 \sim 80$ Celsius \\
Accuracy & $0.1 \% \mathrm{RH}$ & $<+-0.5 \mathrm{Celsius}$ \\
Resolution & $+-1 \% \mathrm{RH}$ & 0.1 Celsius \\
Repeatability & Average: $2 \mathrm{~s}$ & +-0.2 Celsius \\
Sensing period & & Average: $2 \mathrm{~s}$ \\
\hline
\end{tabular}

\section{Moisture Sensor}

Moisture sensors reads the volumetric water content in grain. Since the direct gravimetric measurement of free moisture requires eliminating, drying, and increment of a sample, moisture content sense the volumetric water content ramblingly by using some other property of the grain, such as electrical resistance, dielectric constant, or communication with neutrons, as a substitution for the moisture content. The relation between the measured property and moisture must be standardized and may vary dependent of environmental factors such as temperature, electric conductivity, or humidity. Reproduced microwave energy is affected by moisture and is used for remote sensing in hydrology and agriculture. Portable probe instruments can be used by the manager. Generally, sensor value varies from 0 to 1023 so we need to use the map function to get the sensor value in percentage.

\section{LEDs}

Light emitting diode are just small light bulbs that is suitable into any electrical circuit. LEDs have polarity, which means they will only light up if you position the legs properly. The long leg is typically positive and should connect to a digital pin on the Arduino board. The short leg goes to ground. The bulb of the LED will also typically have a flat edge on this side.

\section{E. GSM Module}

The wireless radio channel is a transceiver device that can receive and transmit information The Global Systems for Mobile Communication (GSM) module allows the embedded system to transmit and receive text messages, transmit data on the General Packet Radio Service (GPRS Modem) network. The GSM module needs an activated SIM card to operate. SIM800, basically with Quad-Band of $800 \mathrm{MHz}$ was selected for this design; it is compact and designed with RS232 level converter circuitry. It has an internal TCP/IP stack via GPRS, very good for SMS, and transfer of data. Three wires present are Tx, Rx, and GND, this module also consists of a built-in voltage regulator. It has a meager power consumption of $1.0 \mathrm{~mA}$ (sleep mode), which is desirable for wireless applications. The GSM/GPRS module is configured and operated through a Serial Peripheral Interface (SPI). SIM800 is a quad-band GSM/GPRS module designed for the global market. It works on frequencies GSM $850 \mathrm{MHz}$, EGSM $900 \mathrm{MHz}$, DCS $1800 \mathrm{MHz}$ and PCS 1900MHz.SIM800 features GPRS multi-slot class 12/ class 10 (optional) and supports the GPRS coding schemes CS-1, CS-2, CS3 and CS-4.SIM800 has 68 SMT pads and provides all hardware interfaces between the module and customers' boards.SIM800 integrates TCP/IP protocol and extended TCP/IP AT commands which are very useful for data transfer applications. This wireless module sends and receives data through radio waves. Like a GSM mobile phone, a GSM modem requires a SIM card from a wireless carrier to operate. GSM Sim800 can accept any GSM network operator SIM card and act just like a mobile phone with its own unique phone number Applications like SMS Control, data transfer, remote control, and logging can be developed easily. The modem can either be connected to the PC serial port directly or to any microcontroller. It can be used to send and receive SMS or make/receive voice calls. A code was developed using Arduino IDE to receive the sensed data from the microcontroller.

\section{F. Wi-Fi Module}

The ESP8266 is a low-cost Wi-Fi chip with a full TCP/IP stack and MCU (microcontroller unit) capability produced by a Shanghai-based Chinese manufacturer. This small module allows microcontrollers to connect to a Wi-Fi network and make simple TCP/IP connections using Hayes style commands. The ESP8285 is an ESP8266 with 1MB of builtin flash, allowing for single-chip devices capable of connecting to $\mathrm{Wi}-\mathrm{Fi}$.

\section{SOFTWARE SUB-SYSTEM}

The embedded system was programmed using $\mathrm{C} / \mathrm{C}++$ programming language, and it controls the flow of instruction in the system implemented on Arduino, The Arduino project offers an integrated development environment (IDE) built on the Processing language project. The Android application was developed using Java programming on the android studio. The application was installed on any Android smartphone with an OS version not less than 4.4 KitKat, giving a user-friendly interface for farmers or any other operator to monitor the storage facility remotely.

The software implementation algorithm is sectioned into the following phase:

\section{A. Simulation}

The system was simulated on an electrical software package known as Proteus Professional 8.6 as shown in Fig. 3. ATmega-1280developed by Arduino.cc was the microcontroller selected to serve as the sensor node processing unit. It supports data up to eight bits and has a $128 \mathrm{~KB}$ internal built-in memory. All the data obtained through respective sensors are processed by the Arduino micro-controller through the channel and digital pins. An Analogue-to-digital converter (ADC) at 10-bit resolution performs the conversion of analogue values from the sensor to digital values for smooth operation by the microcontroller. It converts the voltage measurements in the range of $0-1023$, when a voltage of $5 \mathrm{~V}$ is provided to the probes, a resolution of about $0.005 \mathrm{~V}$ 
$(5 / 1023)$ is obtained. Output data from the Arduino microcontroller is transmitted to the base station via the GSM module. SDcard was incorporated into the device to save data at every instance of time such that data is not lost when the GSM network is unavailable. Fig. 3 shows the system simulation.

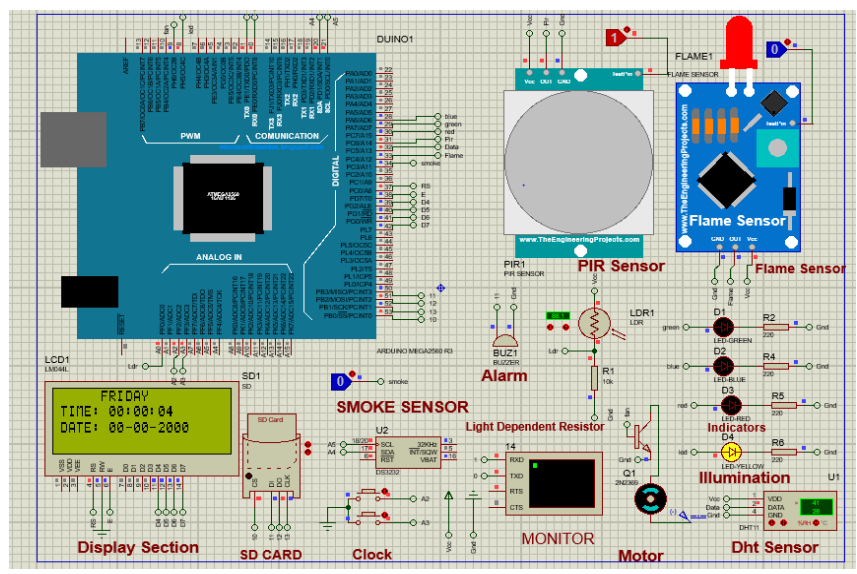

Fig. 3. Device Simulation.

The simulation was carried out with its corresponding code written with $\mathrm{C} / \mathrm{C}^{++}$programming language in the Arduino Integrated Development Environment (IDE) as shown in Fig. 4.

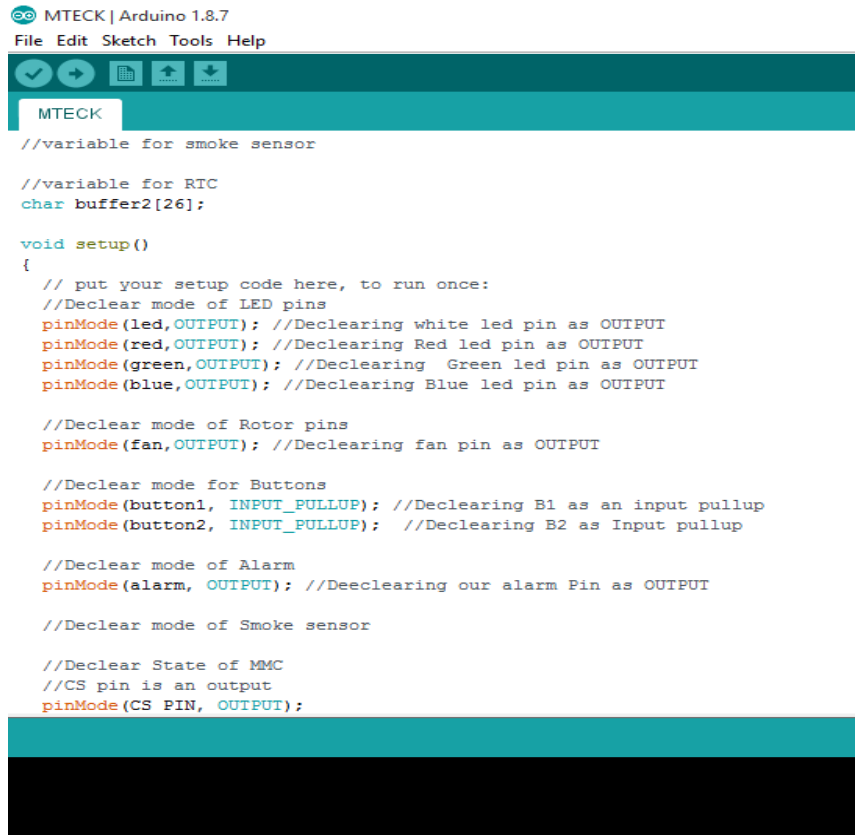

Fig. 4. Arduino Integrated Development Environment (IDE).

\section{B. System Algorithm}

The full system algorithm is as described below:

Step 1: Start the system, turn on a status button to show the system on.

Step 2: Check for SDcard.

Step 3: Checking GSM module connectivity, blink network status led 100ms while searching for network, wait unit network is found if found reduce network status blink rate to $1000 \mathrm{~ms}$.

Step 4: Display the time and date.

Step 5: Checking and calibrate all units and sensors.

Step 6: Read a value from sensors.
Step 7: Send sensor data value to the wifi via wifi module wait for the server response and blink transfer status led.

Step 8: Send a request to on controlling device if values are high.

Step 9: Wait $1000 \mathrm{~ms}$

Step 10: GOTO step 1.

\section{Mobile App Algorithm}

This would be a user-friendly application to help users understand and act on the information provided by the app. The mobile application algorithm will work as follows:

Step 1: Send GET request to the Wifi.

Step 2: Listening to server response.

Step 3: Extract data from the response.

Step 4: Populate Views with value.

Step 5: GOTO, step 1.

Fig. 5 shows the system flowchart.

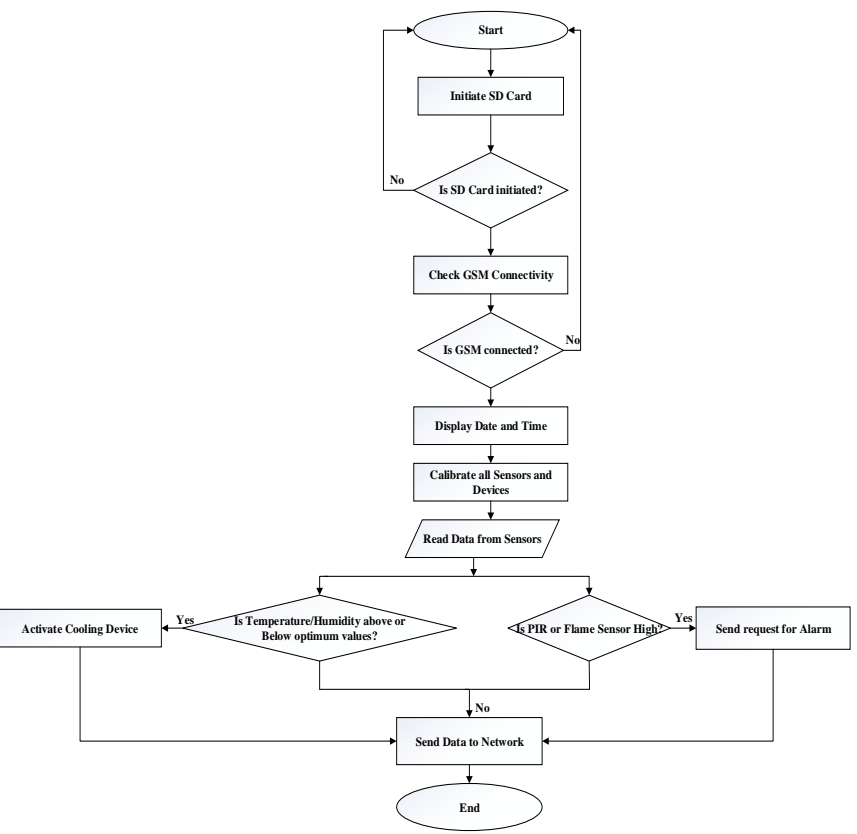

Fig. 5. System Flowchart

Fig. 6 shows the Android Application Flowchart.

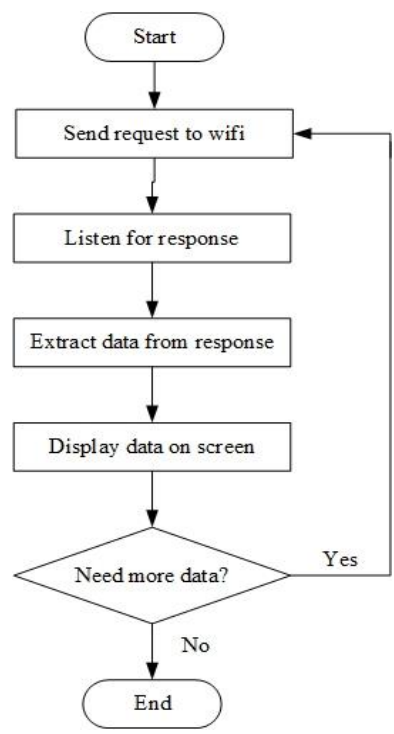

Fig. 6. Android Application Flowchart. 


\section{ANDROID APPLICATION SETUP AND CONFIGURATION}

Android application has been built using different modules required for the application development in Android application IDE. These are built into .apk files based on the project specifications. The build settings comprise of application source code and resource files. Most code and resource files are generated by default, while others will be developed based on developer requirements. The module provides different projects, and it builds settings so that the android module is compiled and packaged into a apk file. The apk file for each app contains all the required information necessary to run the application on a device.

\section{MANAGER's MobiLE APPliCATION DEVELOPMENT}

The Mobile App was implemented using android studios. Android was preferred as a platform for this purpose due to its number of users and its availability. The android studio is powered majorly by java for the logic part and XML for the frontend part. There are different libraries introduced in other to develop a functional and smart android application. The cloud has a restful service that has been designed to handle different forms of HTTP calls including POST and GET. The android application was developed to ease access to the server in the cloud. The application was made with a minimum android targeted platform of 4.0. This infers that the application will run on devices with an android operational system version 4.0 and above but might cause an error or might not run in the lesser version. According to research, $82 \%$ of smartphones devices run on an Android operating system, which additional buttresses the choice of this platform. The basic functionality of this app is the input, output and connection to the web service.

TABLE III: MOBILE APP. FUNCTIONAL REQUIREMENT

\begin{tabular}{cc}
\hline S/N & Description \\
\hline 1 & $\begin{array}{c}\text { The application must be able to read data from the server } \\
\text { Information retrieved from the server must be displayed } \\
\text { in the list view }\end{array}$ \\
3 & $\begin{array}{c}\text { Information retrieved from the server must be populated } \\
\text { in a chart view }\end{array}$ \\
4 & The application must be able to export data in excel \\
format
\end{tabular}

\section{FABRICATION}

All components necessary were purchased locally and the necessary tools required for the construction of the project were purchased locally. During the pre-soldering assembly and testing stage, it was simulated to know the efficiency of the circuit. The circuit was then assembled on a Breadboard to determine the performance of the design. After the assembly of components on a Breadboard, the entire circuit components were transferred to the Vero board and proper soldering was carried out. All connections were properly and neatly soldered to ensure that soldering joints are electrically continuous and firm. The following precautions were taken in the process:

i. The soldering bit was tinned before soldering.

ii. The soldering iron was carefully applied to the soldered joint to prevent overheating. iii. Excess application of soldering lead was avoided to prevent gating of the component next to each other.

Fig. 7 shows the prototype on a breadboard.

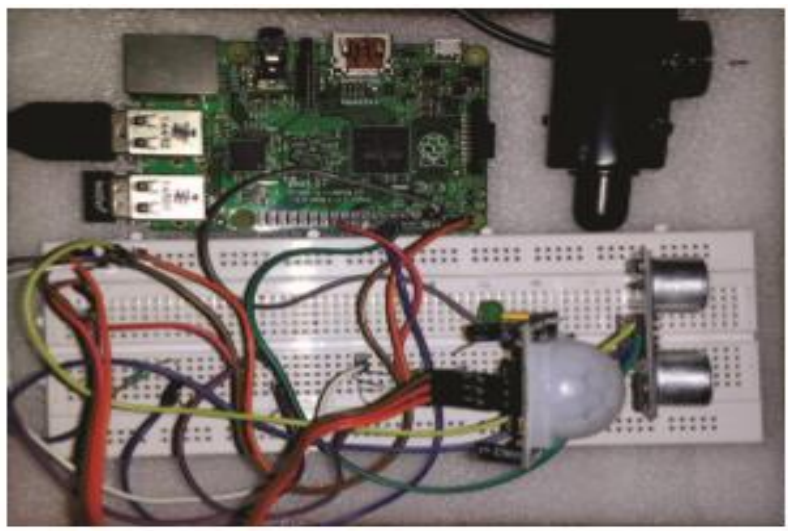

Fig. 7. Screenshot of the Prototype.

\section{EXPERIMENTAL PROCEDURE}

The study was carried out at the Federal Ministry of Agriculture and Rural Development, Strategic grain reserve facility - Ilesa, Osun state. The study started with 100 bags of Zea mays, which was divided into two, 50 bags in a storage facility with the deployed device and the other 50bags was placed on normal storage without the device. The initial weight of maize per bag is $50 \mathrm{~kg}$ and the initial moisture content of $13 \%$. The storage facility is a standardized warehouse in which ventilation facilities and favourable construction properties are put into consideration. The warehouse was a well-designed bag storage system. The system is easy to manage, cheap and efficient and well adapted to the existing infrastructure in most countries. In other to maintain good storage for maize, the following parameters were maintained as recommended, they include:

a. Temperature: The cooling effect of radiation from the store, outside temperatures, heat produced by the respiration of the grain in the store affects temperature within a storage facility. According to [9], [10] the optimum temperature for the good storage of maize is $\left(18-27^{\circ} \mathrm{C}\right)$ to which the device was adjusted before deploying.

b. Humidity: The amount of water vapour in the air is affected by wind and by rainfall. And according to the study, the optimum humidity for the good storage of maize is (60-70\%) [9].

c. Moisture content: High moisture content leads to storage problems because it encourages problems created by fungi and pests. Maize will normally be harvested at a moisture content of 18-25 per cent (wb), after drying the required moisture content for Maize storage is $13 \%$ [10]. Moisture content is the amount of water molecule contained in an agricultural material. It could be defined on a wet basis (M.C $\mathrm{wb}_{\mathrm{wb}}$ ) or dry basis $\left(M . C_{d b}\right)$ it is expressed either in ratio or percentage.

$$
\begin{aligned}
& \text { M. } C_{\mathrm{wb}}=\frac{\text { weight of water }}{\text { weight of wet product }} \\
& \text { M. } \mathrm{C}_{\mathrm{db}}=\frac{\text { weight of water }}{\text { weight of dry product }}
\end{aligned}
$$


M. $\mathrm{C}_{\mathrm{wb}}$ is used for commercial purposes while M.C $\mathrm{db}_{\mathrm{db}}$ is used for scientific purposes. Their relationship is shown below:

$$
\begin{aligned}
& M \cdot C_{\mathrm{db}}=1-\frac{M \cdot C w b}{M \cdot C w b} \\
& \mathrm{M} \cdot \mathrm{C}_{\mathrm{wb}}=1+\frac{M \cdot C d b}{M \cdot C d b}
\end{aligned}
$$

\section{Statistical ANALYSIS}

Statistical descriptions were used to analyze the effect of physical environmental factors on maize storage. The transformed data were first analyzed using one-way repeated measures ANOVA) to evaluate mean differences at 0.05 significant levels. Results with $(p \leq 0.05)$ were considered significantly different [8]. it compares grain moisture content, per cent discoloured grain and weight loss during the period of study.). The statistical analyses were done using IBM SPSS Inc. (Windows version 20).

In other to analyze the following parameter was calculated to compare the storage facility with the deployed device and the normal silo normal way of storage.

The device gives the data update of the storage facility every second, therefore the arithmetic mean is used to calculate the mean value per day.

Mean $=\frac{\text { sum of the observations }}{\text { number of the observations }}$, therefore $\chi=\frac{\sum x}{n}$.

discolored grain $(\%)=\frac{\text { number of discoloured grain }}{\text { total number of grain }} \times 100[10]$

Weight loss $(\%)=\frac{[(W u \times N s)-(W s \times N u)]}{W u \times(N u+N s)} \times 100$

where $\mathrm{Wu}=$ weight of unspoiled grain, $\mathrm{Wd}=$ weight of spoiled grain.

$\mathrm{Nu}=$ Number of unspoiled grain, $\mathrm{Nd}=$ number of spoiled grain.

\section{RESUlt AND Discussion}

\section{A. Sensors Data from the Storage Facility}

The developed device was deployed on the storage facility to measure values such as moisture content, temperature and humidity as indicated with their respective sensor to monitor the stored grains. Consequently, the security sensors such as the flame sensor and the Passive infrared sensor were able to give alarm when high temperatures are sensed and when there is an intrusion in the storage facility respectively. Figure 8 shows that the developed device has a precise reading having date and time to measurement obtained from the MYSQL database hosted online at Federal ministry of agriculture and rural development, Strategic grain reserve facility - Ilesa, Osun state.

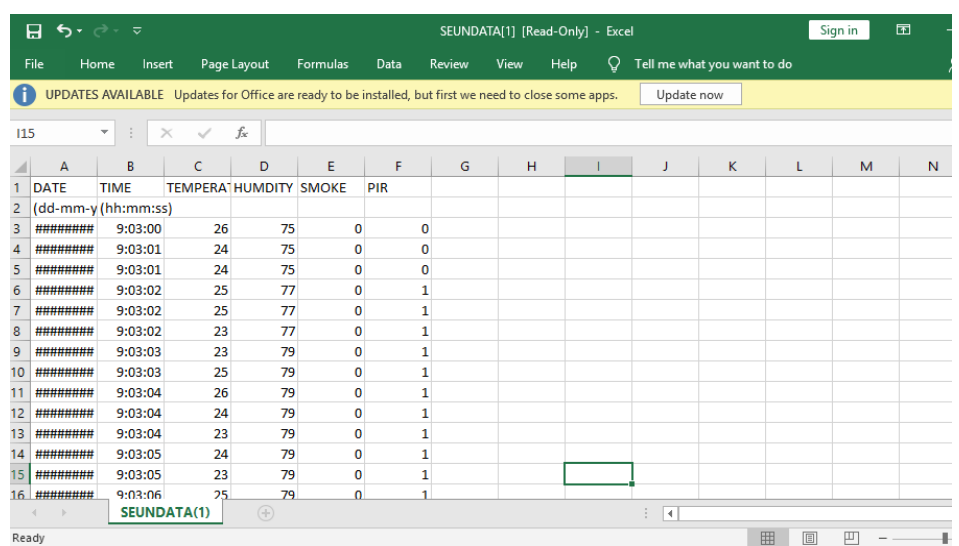

Fig. 8. Overview of sensor values from the sensor nodes logged to the online database.

\section{B. Evaluation of the IoT based Smart Monitoring System}

The developed IoT-based smart monitoring device was evaluated through weight performance and statistical analysis of physical parameters of the environment affecting the weight of the stored maize.

As stated by [7], Grain to be stored in bins or sacks may have too high a temperature or too high a moisture content, or both. If ambient temperatures are low, then air by itself can cool the stored grain enough to avert mould and pest damage while the moisture content is being gradually reduced to a safe level. If the air temperature is too high (over $10^{\circ} \mathrm{C}$ ), drying may be hurried by heating, as heating the air further rises its capacity to absorb moisture. For good storage of maize, the optimum temperature range is between $18-27^{\circ} \mathrm{C}$ and the optimum humidity range is between $62-70 \%$. Grain is generally harvested at a moisture content of $18-25$ per cent (wb), although it can be significantly higher or lower depending on many factors (such as the stage of maturity, season, weather pattern and drying facilities). The longer you store your grain, the lower the moisture content should be. Maize stored over a year should have a moisture content of no more than $13 \%$ at $27{ }^{\circ} \mathrm{C}$ of temperature and $70 \%$ of humidity which is the maximum acceptable level for storage of any sample [10000].

TABLE IV: STORAGE FACILITY REQUIREMENT FOR MAIZE STORAGE

\begin{tabular}{ccc}
\hline Parameters & $\begin{array}{c}\text { Maize stored with } \\
\text { the device }\end{array}$ & $\begin{array}{c}\text { Maize stored } \\
\text { without device }\end{array}$ \\
\hline Number of Bags & 50 & 50 \\
Size of Bag $(\mathrm{kg})$ & 50 & 50 \\
Moisture content $(\%)$ & 13 & 13 \\
Temperature $\left({ }^{\circ} \mathrm{c}\right)$ & $18-27$ & $18-27$ \\
Humidity $(\%)$ & $62-70$ & $62-70$ \\
\hline
\end{tabular}

The temperature and humidity of the storage facility where the device was deployed were monitored at the required values in Table IV. The long period of storage above or below this required temperature causes a great influence on the respiration rate of the stored maize and pest organisms as well as on the relative humidity and the maize moisture content. The high temperature above the required temperature is said to be ideal living conditions for insect pest and high relative humidity make the maize develop fungi, which lead to mould. At the end of the research study, the temperature, the relative humidity, and the moisture content of the stored products are closely interrelated see Table V. 
TABLE V: SHOWS THE EFFECT OF TEMPERATURE AND HUMIDITY ON THE STORED MAIZE

\begin{tabular}{ccc}
\hline Parameters & $\begin{array}{c}\text { Maize stored with } \\
\text { the device }\end{array}$ & $\begin{array}{c}\text { Maize stored without } \\
\text { device }\end{array}$ \\
\hline Number of Bags & 50 & 50 \\
Size of Bag (kg) & 50 & 50 \\
Initial moisture content $(\%)$ & 13 & 13 \\
Initial weight/ per bag (kg) & 50 & 50 \\
Final moisture content $(\%)$ & 13.79 & 17.00 \\
Final weight / per bag (kg) & 47.38 & 41.05 \\
\hline
\end{tabular}

The values of the final moisture content and the final weight / per bag at the end of the implementation shows the effect of temperature and humidity on the stored maize in both conditions. Due to the season of storage, which is the rainy season, the humidity tends to be high in most data updates and temperature tends low.

\section{Online Data Logging by the Device}

The manager having access to the status of the storage facility, anytime, anywhere from any location is a huge step to put into quick action necessary for optimum physical environmental factors of the storage facility and as well as the shelf life of grain (maize). Data obtained from the sensor nodes was logged into a database hosted online in the cloud through the GSM module. Table VI shows the developed algorithms to achieve data logging. The base station continuously checks its wireless port for the readiness of sensor data from the sensor nodes on the farm and logged it into the online MYSQL database in the cloud using the application protocol interface (API) key. There is a need to automate information sent to the server in other to inform the manager set threshold level has been reached and the ventilation system is initiated to maintain the temperature and humidity in the facility to avert poor yield. Studies show that the optimum maintained temperature for good maize storage is $18-27{ }^{\circ} \mathrm{C}$, the optimum humidity is $(62-70 \%)$ and the optimum moisture content for stored maize is between $13 \%$ and $14 \%$.

TABLE VI: DATA LOGGING ALGORITHM

\begin{tabular}{l}
\hline GSM/GPRS Data Logging Algorithm \\
1: Procedure Maize monitoring \\
2: Function getdatetime \\
3: get the current time \\
4: get the date today \\
5: Return [dateToday,Time] \\
6: ConFigureuration \\
7: GPRS Connection \\
8: If connection exists proceed to 12 \\
9: else: Network Error \\
10: Send command to Arduino to restart the system \\
11: Repeat step 1-8, if yes move to step 12 \\
12: Initialize Serial Port \\
13: Data logging through API (http://api/logquery.php?) \\
14: Write data to MSQL online database \\
15: Repeat after every 1min
\end{tabular}

\section{Mobile App}

The mobile app is a software application designed to run on a mobile device. The mobile application was implemented using android studios. Android was preferred as a platform for this purpose due to its number of users and its availability. Fig. 9 shows the Mobile app in its development phase. The mobile app interface was developed in a user's friendly format in which the manager at the storage facility will be able to understand. Fig. 9 shows the interface of the mobile app populated by the data obtained from the storage facility.

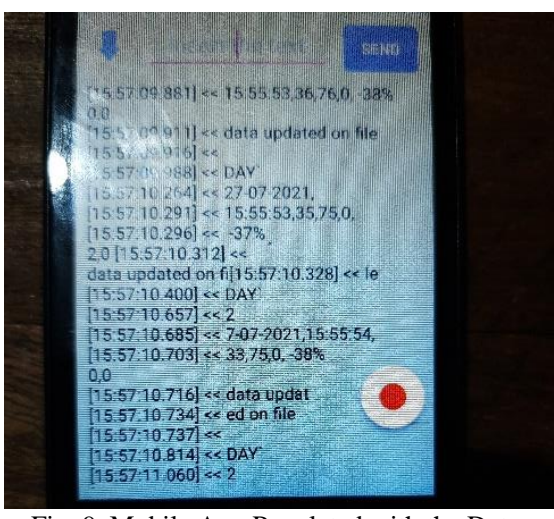

Fig. 9. Mobile App Populated with the Data.

\section{E. Statistical Analysis}

The device gives the data update of the storage facility every second, therefore the arithmetic mean is used to calculate the mean value per day as given below, i.e.

Mean $=\frac{\text { sum of the }}{\text { number of the observations }}$

of the therefore $\chi=\frac{\sum x}{n}$.

TABLE VII: COMPARISON OF THE MEAN AMBIENT TEMPERATURE AND HuMIDITY WITH THE MEAN TEMPERATURE AND HUMIDITY OF THE

\begin{tabular}{|c|c|c|c|c|}
\hline \multicolumn{5}{|c|}{ STORAGE FACILITY } \\
\hline DAY & M.A.T & M.A.H & M.S.T & M.S.H \\
\hline 1 & 30 & 80 & 26 & 72 \\
\hline 2 & 29 & 85 & 24 & 78 \\
\hline 3 & 28 & 70 & 23 & 68 \\
\hline 4 & 25 & 74 & 19 & 70 \\
\hline 5 & 27 & 86 & 23 & 77 \\
\hline 6 & 29 & 81 & 25 & 76 \\
\hline 7 & 30 & 60 & 30 & 52 \\
\hline 8 & 32 & 70 & 18 & 64 \\
\hline 9 & 30 & 80 & 28 & 74 \\
\hline 10 & 29 & 60 & 31 & 50 \\
\hline 11 & 27 & 60 & 30 & 52 \\
\hline 12 & 26 & 78 & 21 & 73 \\
\hline 13 & 25 & 78 & 23 & 71 \\
\hline 14 & 25 & 80 & 17 & 72 \\
\hline 15 & 27 & 82 & 20 & 71 \\
\hline 16 & 27 & 90 & 21 & 77 \\
\hline 17 & 26 & 81 & 23 & 73 \\
\hline 18 & 24 & 79 & 22 & 70 \\
\hline 19 & 30 & 80 & 28 & 75 \\
\hline 20 & 24 & 78 & 20 & 71 \\
\hline 21 & 29 & 80 & 27 & 69 \\
\hline 22 & 30 & 79 & 28 & 68 \\
\hline 23 & 28 & 76 & 26 & 70 \\
\hline 24 & 31 & 76 & 26 & 70 \\
\hline 25 & 30 & 77 & 27 & 76 \\
\hline 26 & 27 & 85 & 27 & 71 \\
\hline 27 & 30 & 82 & 25 & 70 \\
\hline 28 & 29 & 76 & 28 & 52 \\
\hline 29 & 30 & 60 & 30 & 56 \\
\hline 30 & 28 & 65 & 30 & 68 \\
\hline 31 & 29 & 74 & 25 & 71 \\
\hline 32 & 27 & 83 & 26 & 70 \\
\hline 33 & 25 & 76 & 24 & 68 \\
\hline 34 & 26 & 77 & 23 & 70 \\
\hline 35 & 27 & 83 & 24 & 71 \\
\hline 36 & 30 & 68 & 25 & 60 \\
\hline 37 & 28 & 79 & 27 & 70 \\
\hline 38 & 27 & 80 & 24 & 74 \\
\hline 39 & 28 & 78 & 25 & 70 \\
\hline
\end{tabular}

where M.A.T is the Mean Ambient Temperature, M.S.T is the Mean of Storage facility Temperature, M.A.H is the Mean Ambient Humidity and M.S.H is the Mean Storage facility Humidity. 


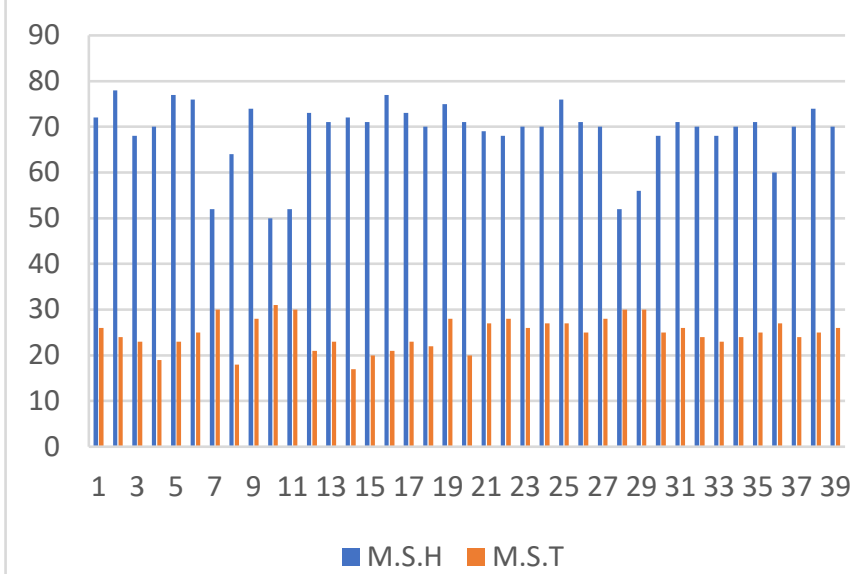

Fig. 10. Graphical View of the sensed data in the Storage facility.

There is an increase in humidity in the storage facility mostly more than the device threshold (i.e., optimum humidity set for good storage) due to as storage facility being not airtight and the ambient humidity is high due to the rainy season of implementation. Consequently, there are days that the mean ambient humidity and the mean humidity of the storage facility are low which is considered as sunny days, there was a slight increase in their respective temperature. The storage facility temperature and humidity were maintained during the implementation of the device.

Table VIII shows the decrease in the weight of the stored maize both at the storage facility with the device deployed and the storage facility without the device. Where the following formula was employed to know the percentage of weight loss during the period of implementation of the device.

$$
\text { Weight loss }(\%)=\frac{[(W u \times N d)-(W d \times N u)]}{W u \times(N u+N d)} \times 100
$$

This table also shows the difference in the decrease in both storage facilities. At the storage facility where the device was deployed, the decrease is minimal when compared with the storage facility without the device because appropriate measures, (i.e., initiating the ventilating system when the humidity and temperature are above the required stored maize values) are made to maintain the required physical parameter of the facility.

TABLE VIII: EFFECT OF TEMPERATURE AND HUMIDITY ON THE STORED

\begin{tabular}{cccc}
\multicolumn{3}{c}{ MAIZE WEIGHT } \\
\hline DAY & A.W.D & A.W.W.D & Differents \\
\hline 1 & 50 & 50 & 0 \\
2 & 50 & 50 & 0 \\
3 & 50 & 49.9 & \pm 0.1 \\
4 & 49.9 & 49.7 & \pm 0.2 \\
5 & 49.9 & 49.65 & \pm 0.25 \\
6 & 49.7 & 47.6 & \pm 0.80 \\
7 & 49.69 & 48.9 & \pm 0.89 \\
8 & 49.6 & 48.7 & \pm 0.90 \\
9 & 49.6 & 48.4 & \pm 1.20 \\
10 & 49.55 & 48.2 & \pm 1.35 \\
11 & 49.5 & 48 & \pm 1.50 \\
12 & 49.44 & 47.8 & \pm 1.64 \\
13 & 49.4 & 47.55 & \pm 1.85 \\
14 & 49.32 & 47.4 & \pm 1.92 \\
15 & 49.1 & 47.25 & \pm 1.85 \\
16 & 49 & 47.12 & \pm 1.88 \\
17 & 48.91 & 46 & \pm 2.91 \\
18 & 48.88 & 46.5 & \pm 2.38 \\
\hline
\end{tabular}

\begin{tabular}{lccl}
\hline 19 & 48.8 & 46.32 & \pm 2.48 \\
20 & 48.72 & 46.11 & \pm 2.61 \\
21 & 48.65 & 46.05 & \pm 2.60 \\
22 & 48.54 & 45.81 & \pm 2.73 \\
23 & 48.5 & 45.71 & \pm 2.79 \\
24 & 48.43 & 45.6 & \pm 2.83 \\
25 & 48.35 & 45.4 & \pm 2.95 \\
26 & 48.28 & 45.25 & \pm 3.03 \\
27 & 48.11 & 45.13 & \pm 2.98 \\
28 & 48 & 44.85 & \pm 3.15 \\
29 & 47.95 & 44.34 & \pm 3.61 \\
30 & 47.92 & 44.2 & \pm 3.72 \\
31 & 47.88 & 44.01 & \pm 3.87 \\
32 & 47.76 & 43.7 & \pm 4.06 \\
33 & 47.6 & 43.6 & \pm 4.00 \\
34 & 47.45 & 43.2 & \pm 4.25 \\
35 & 47.4 & 43 & \pm 4.4 \\
36 & 47.4 & 42.6 & \pm 4.8 \\
37 & 47.38 & 42.12 & \pm 5.26 \\
38 & 47.35 & 42 & \pm 5.35 \\
39 & 47.3 & 41.41 & \pm 5.89 \\
\hline
\end{tabular}

Where A.W.D is the Average weight of maize with Device (KG) and A.W.W.D is the Average weight of maize without Device (KG).

TABLE XI: EFFECT OF TEMPERATURE AND HUMIDITY ON THE MOISTURE CONTENT OF THE STORED MAIZE. ACCORDING To [4],[7], THE OPTIMUM MOISTURE CONTENT FOR STORING MAIZE IS BETWEEN 13\% AND 14\%

\begin{tabular}{|c|c|c|}
\hline DAY & $\begin{array}{l}\text { Moisture content with } \\
\text { Device }(\%)\end{array}$ & $\begin{array}{c}\text { Moisture content without } \\
\text { Device }(\%)\end{array}$ \\
\hline 1 & 13 & 13 \\
\hline 2 & 13 & 13 \\
\hline 3 & 13 & 13.1 \\
\hline 4 & 13 & 13.15 \\
\hline 5 & 13.05 & 13.2 \\
\hline 6 & 13.08 & 13.28 \\
\hline 7 & 13.1 & 13.34 \\
\hline 8 & 13.15 & 13.42 \\
\hline 9 & 13.16 & 13.5 \\
\hline 10 & 13.19 & 13.62 \\
\hline 11 & 13.22 & 13.78 \\
\hline 12 & 13.23 & 14.15 \\
\hline 13 & 13.27 & 14.25 \\
\hline 14 & 13.29 & 14.3 \\
\hline 15 & 13.31 & 14.45 \\
\hline 16 & 13.34 & 14.62 \\
\hline 17 & 13.37 & 14.7 \\
\hline 18 & 13.39 & 15.2 \\
\hline 19 & 13.41 & 15.45 \\
\hline 20 & 13.43 & 15.65 \\
\hline 21 & 13.45 & 15.9 \\
\hline 22 & 13.48 & 16.15 \\
\hline 23 & 13.52 & 16.28 \\
\hline 24 & 13.55 & 16.5 \\
\hline 25 & 13.55 & 16.6 \\
\hline 26 & 13.59 & 16.8 \\
\hline 27 & 13.62 & 17 \\
\hline 28 & 13.65 & 17.2 \\
\hline 29 & 13.67 & 17.5 \\
\hline 30 & 13.69 & 17.7 \\
\hline 31 & 13.72 & 17.8 \\
\hline 32 & 13.74 & 17.95 \\
\hline 33 & 13.76 & 18 \\
\hline 34 & 13.76 & 18.2 \\
\hline 35 & 13.79 & 18.3 \\
\hline 36 & 13.81 & 18.5 \\
\hline 37 & 13.83 & 18.7 \\
\hline 38 & 13.85 & 18.81 \\
\hline 39 & 13.87 & 18.9 \\
\hline
\end{tabular}

During the period of implementation of the device at the storage facility, the humidity tends to be higher due to the rainy season of the implementation and monitoring. This factor is what contributed to the increase in moisture content of the stored maize. The storage facility with the deployed device was able to maintain the facility by sucking out the 
discharges of excessive humidity from the facility when initiating the ventilating system. At the end of the implementation, the storage facility with the deployed device was able to maintain the daily humidity which makes the moisture content conform with required moisture content values for safe storage. Table XI shows the rapid increase of the moisture content of the facility with device M.C.D and the moisture content of the facility without device M.C.W.D.

\section{CONCLUSION}

In conclusion, for a good storage of maize grain, environmental factors such as temperature, humidity and moisture content must be controlled. These factors are the main influences of maize deterioration because they affect moulds, insects, and other pests, which can result in huge losses of maize grain in a very short time. To avoid mycotoxin contamination, maize should be monitored regularly to assure safe storage conditions, hence, maize contaminated by fungi and moulds not only render grains unfit for human consumption by discolouration but can also lead to toxin production. IoT-Based smart security and monitoring device for the agricultural product (maize) developed in the study was able to monitor and effectively provide efforts necessary for the optimum post-harvest operation of maize which enhances maize storage efficiency. A wireless sensor network was developed to monitor the physical environmental factors and $\log$ data retrieved to an online database in the cloud. A user-friendly mobile application was designed to access the information in the cloud to give the manager the status and variation changes of the storage facility in real-time and initiate the required decision. The study also gives a clear insight on biological factors responsible for the low storage of maize such as (grain characteristics, microorganisms, insects, mites, rodents, birds) and how this factor can be managed. The result of the study established that there is a slight difference between the Temperature $\left(17-31^{\circ} \mathrm{C}\right)$ and Humidity $(52-78 \%)$ obtained from the device and optimum Temperature $\left(18-27^{\circ} \mathrm{C}\right)$ and Humidity $(62-70 \%)$ required for maize storage which makes it a better method when compared with the conventional method of storing maize. The result obtained further shows that temperature, humidity, and moisture content contributed to losses in weight of the maize stored if not monitored and maintained during the research period.

\section{REFERENCES}

[1] Rekha J. S. An approach for the development of a sensing system to monitor contamination stored grain. 6th international conference on signal processing and integrated networks (SPIN), 2019;8(6):880-884.

[2] Ho S.H; Rossaria H.H; Rahman M.M Numerical simulation of temperature and velocity in a refrigerated warehouse. International Journal of Refrigeration, 2010; 33(5):1015-1025.

[3] Hellevang K. J. Natural Air-low temperature crop drying. North Dakota State University (NDSU) extension service. Extension bulletin 35 (revised), 2005. [www.ag.ndsu.edu/graindrying/documents/eb35.pdf].

[4] Vermesan P. F. Internet of things strategic research roadmap. Internet of things: Global technological and Societal Trends, 2011; 3(6):9-52.

[5] Pena-Lopez I. The Internet of Things. Itu internet report 2005;3(3):5965.

[6] Pallavi S. and Smruti R. S. Internet of Things. Architectures, Protocols, and Applications, 2017; 1-25.
[7] Zar J.H. Biostatistical Analysis. $5^{\text {th }}$ Edition, Prentice-Hall, Upper Saddle River, ISBN-13:9780131008465, 2010; pp. 960. New Jersey, Englewood, U.S.A.

[8] Adeyeba A.O. Storage, Preservation and Processing of farm produce. Food Science and Quality management. ISSN 2224-6088(paper) ISSN 2225-0557, 2014;27:28-32.

[9] Boxall R. A. Damage and loss caused by the larger grain borer Prostephanus truncatus, Integrated Pest Management Reviews, 2002;7(2):105-121.

[10] Paulsen M.R.; Odekirk W.L. Guide to planning grain drying, handling and storage systems. Applied Engineering in Agriculture, 2000; 16(5): 513.

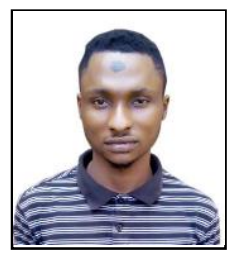

Oluwaseun Isaiah Ekuewa is a research student at Department of Electrical and Electronics Engineering (Communication Option) in Federal University of Technology Akure, Nigeria. A diligent student ready to make more impact in my country and the whole world at large. 